\title{
Study of Induction of Labour with Oral Misoprostol and its Maternal and Perinatal Outcome
}

\section{Priya Pratapan Nair ${ }^{1}$, Mugdha L Jungari2*, Mahima R. Tiwari ${ }^{3}$, Lata Kanyal Butola ${ }^{4}$}

\begin{abstract}
'Assistant Professor, Department of Obstetrics and Gynecology, Datta Meghe Medical College, Shalinitai Meghe Hospital and Research Centre, (DMIMS) Nagpur-441110; 'Associate Professor, Department of Obstetrics and Gynecology, Datta Meghe Medical College, Shalinitai Meghe Hos-

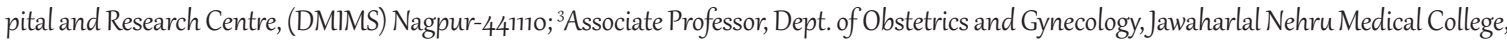
Datta Meghe Institute of Medical Sciences, Sawangi, Wardha-442001; ${ }^{4}$ Tutor, Department of Biochemistry, Jawaharlal Nehru Medical College, Datta Meghe Institute of Medical Sciences, Sawangi, Wardha-442001.
\end{abstract}

\section{ABSTRACT}

Background: One great challenge in obstetric care is labour induction. Oxytocin has been used for labor induction since very long, but with high rates of failed induction. Oral misoprostol as an induction of labour (IOL) agent is rapidly gaining popularity in resource-limited settings because it is cheap, stable at ambient temperatures, and logistically easier to administer compared to dinoprostone and oxytocin. We aim to investigate the safety and effectiveness of oral misoprostol for induction of labour in our hospital setup.

Material and Methods: Women with a singleton pregnancy in cephalic presentation and an unfavorable cervix who gave written informed consent and were fitting in the inclusion criteria were administered oral misoprostol, commencing at 25 mcg oral once every 4 hours for maximum 6 doses. The primary outcomes studied were i) the proportion of women delivering vaginally within $24 \mathrm{~h}$ of oral misoprostol administration, and ii) maternal and perinatal outcomes following induction with misoprostol. A retrospective Study of the data collected from September 2019 till April 2020 at Shalini Meghe Hospital and Research Centre, Wanadongri, Hingna, Nagpur was conducted where 188 women who came under the criteria were induced with misoprostol and outcomes were measured in the form of rate of normal vaginal delivery, maternal complications, and neonatal outcomes.

Results: Total 188 patients were studied retrospectively. Vaginal deliveries were obtained in $65.95 \%$ of patients within 24 hours of induction. The cesarean section rate was $34.04 \%$. The common cause of induction of labour was postdate pregnancy $49.46 \%$. The response of patients with low bishop's score was less with more doses required with longer induction to delivery rate and more chances of cesarean section.

Conclusion: The oral misoprostol regimen for IOL described in the present study is safe, effective, and logistically feasible to administer in a resource-limited setting.

Key Words: Induction of labour, Misoprostol, Perinatal, Oxytocin

\section{INTRODUCTION}

One of the greatest challenges in obstetric care is the induction of labour. The common methods of induction of labour include amniotomy, mechanical dilation with a balloon catheter and use of pharmacological drugs as misoprostol, dinoprostone, and oxytocin.

For the majority of the women, labour starts spontaneously at or near term and results in vaginal delivery, however because of medical or obstetrics complications of pregnancy, labour induction is often required ${ }^{1}$. Induction of labour is the artificial initiation of labour before its spontaneous onset for the purpose of delivery of the fetoplacental unit using mechanical or pharmacologic methods. ${ }^{2}$ The success of labour induction depends on the cervical status at the time of induction. It is generally predicted that the patients with a poor Bishop's score have unacceptably higher rates of failure of induction. ${ }^{3}$ The goal of labour induction is to stimulate uterine contractions before the spontaneous onset of labour, resulting in vaginal delivery. ${ }^{4}$

The search for an ideal agent, timing, and route of administration for the induction of labour has been an ongoing process.

\section{Corresponding Author:}

Dr. Mugdha L Jungari, Associate Professor, Department of Obstetrics and Gynecology, Datta Meghe Medical College, Shalinitai Meghe Hospital and Research Centre, (DMIMS) Nagpur-441110. E-mail: Ambad.sawan@gmail.com

ISSN: 2231-2196 (Print)

Received: 26.05 .2020
ISSN: 0975-5241 (Online)

Revised: 19.06 .2020
Accepted: 01.07 .2020 
Oxytocin has been the commonly used agent in patients with favorable cervix it is not suitable for patients with unfavorable cervix due to high rates of failed induction leading to cesarean section. ${ }^{5}$ Misoprostol is a prostaglandin $\mathrm{E}_{1}$ analogue (methyl11 a 16 - dihydroxy- 16 methyl- 9- oxoprost- 13 enloate).

'Misoprostol' licensed primarily for the prevention and treatment of non-steroidal anti-inflammatory drug-induced ulcers of the gastrointestinal tract is a promising agent for labour induction. ${ }^{6}$ Misoprostol has uterotonic and cervical ripening action. Its effect has led it to be used for termination of unwanted pregnancy, management of incomplete abortions, induction, and augmentation of labour and treatment of postpartum haemorrhage ${ }^{7}$. Misoprostol is also included by WHO as an essential medicine list on several indications including labour induction ${ }^{7}$. Orally administered misoprostol has several publications been shown to be an effective method for induction of labour comparable to oxytocin and dinoprostone gel. ${ }^{7,8,9}$.

Misoprostol is conveniently administered through the oral, sublingual, buccal, vaginal, and rectal routes. ${ }^{6}$ It is inexpensive, easily stored at room temperature, and has few systemic side effects. Several randomized trials of labour with misoprostol have been undertaken ${ }^{10-16}$.

Taking the advantage of the short life of misoprostol, in the present study, we planned to study the outcome of induction of labour with oral dose of $25 \mathrm{mcg}$ of Misoprostol at 4 hourly interval and its maternal and perinatal outcome in the form of induction delivery interval, rate of vaginal delivery, and neonatal outcome.

\section{MATERIAL AND METHODS}

The study was conducted retrospectively based on the data collected on 188 pregnant women in Department of Obstetrics and Gynecology, Datta Meghe Medical College Shalinitai Meghe Hospital and Research Centre, Wanadongri, Hingna, Nagpur in collaboration with Jawaharlal Nehru Medical College, Datta Meghe Institute of Medical Sciences over a period of eight months (September 2019 to April 2020).

A detailed case presentation in the outpatient department, was done using the SNAPPS technique ${ }^{17}$. Detailed history followed by general physical examination was done to rule out any cardio- respiratory, hepatic, and renal disease, obstetrical examination included $\mathrm{P} / \mathrm{A}$ - for fundal height, lie, presentation, and fetal heart sound. $\mathrm{P} / \mathrm{V}$ - examination was done for assessing bishop's score and pelvis. Routine biochemical investigations include $\mathrm{ABO} / \mathrm{Rh}, \mathrm{Hb}, \mathrm{BT}, \mathrm{CT}$, Urine examination and obstetrical USG was done. Then the patient was administered oral misoprostol $25 \mathrm{mcg}$ after taking written informed consent and fulfilling the inclusion criteria. Misoprostol was repeated 4 hourly after assessing the cervical score and the maternal and fetal conditions in utero. The maximum dose of miso given was 6 doses 4 hourly.

The patient was monitored on a cardiotocograph for 30 minutes after the instillation of a dose of misoprostol and as and when required.

The patient was considered to be in active labor if she had painful uterine contractions of $3 / 10 \mathrm{~min}$ of $40 \mathrm{~s}$ duration.

The women were assessed per vaginally under asepsis 4 hours after the last misoprostol dose.

\section{Inclusion criteria}

- $\quad$ Pregnant women (primi and multigravida) at $>34$ weeks of period of gestation for induction of labour.

- $\quad$ Post date, pregnancy-induced hypertension, term and preterm prelabour rupture of membrane, preeclampsia, oligohydramnios, and intrauterine growth restrictions.

- $\quad$ Singleton pregnancy

- Cephalic presentation

- Bishop Score $<6$

- Reactive non-stress test

- Clinically adequate pelvis.

\section{Exclusion criteria}

- Non-reassuring fetal heart pattern

- Contraindications for vaginal delivery (placenta previa, active herpes infection, cephalopelvic disproportion).

- Multiple pregnancies.

- Malpresentation

- Heart disease in mother

- Previous uterine scar, Myomectomy, Hysterotomy, and Known allergy to prostaglandins.

- $\quad$ Patients not giving consent.

\section{Repeat dose was administered if}

- $\quad$ Bishop score $<8$

- Uterine contractions of less than moderate intensity for $<30$ seconds duration with a frequency of $<3$ per 10 minutes

- Cervix unfavorable for amniotomy.

Amniotomy was done if cervix was $>3 \mathrm{~cm}$ dilated. Oxytocin was administered if after amniotomy, the patient failed to have good/moderate uterine contractions with a frequency of at least 3 per 10 minutes and at least 2 hours after the last dose of misoprostol. If the cervix was not favourable for the artificial rupture of membranes after the stipulated six doses, the induction was considered to have failed.

A further dose was withheld in case of tachysystole, hypertonus or hyperstimulation or if the patient was in progressive active labor and spontaneous rupture of membranes. 
Patients were monitored till the patient delivered vaginally or by Caesarean section. The outcome was measured as primary and secondary outcome

\section{Primary outcomes}

- Time taken from administration of first dose to vaginal delivery.

- Mode of delivery.

\section{Secondary outcomes}

- Number of doses required

- Need for Oxytocin augmentation

- Incidence of tachsystole, hyper tonus, and hyperstimulation.

- Neonatal outcomes- Apgar score at 5 minutes, presence of meconium, need for resuscitation, admission in NICU.

- Maternal outcome in terms of abruption, postpartum haemorrhage, blood transfusion, and sepsis.

\section{RESULT AND OBSERVATIONS:}

The total of 188 cases was studied and results were as follows:

In demographic data, the maximum no. of patients was of age group 21-25 (60.6\%) followed by $26-30$ yrs $(28.72 \%)$.

Out of the 188 inductions done, 136 (72.34\%) were primigravida and rest were multigravida with previous normal vaginal deliveries.

\section{Table 1: Demographic data}

\begin{tabular}{lcc} 
Age & $\mathbf{N}(188)$ & Percentage \\
$<20$ yrs & 4 & $2.12 \%$ \\
$21-25$ yrs & 114 & $60.6 \%$ \\
$26-30$ yrs & 54 & $28.72 \%$ \\
$>30$ yrs & 16 & $8.51 \%$ \\
\hline
\end{tabular}

\section{Table 2 : Gravida of the women}

\begin{tabular}{lcc} 
Gravida & N (188) & Percentage \\
Primigravida & 136 & $72.34 \%$ \\
Multigravida & 52 & $27.65 \%$ \\
\hline
\end{tabular}

It was observed that the rate of vaginal deliveries after misoprostol induction was $65.95 \%$ which was significant and the LSCS rate was $34.4 \%$. The percentage of multigravida who underwent LSCS was 25\% (13 cases). Most patients had a poor bishop's score. $10 \%$ of patients had pre-induction modified bishop's score $0-2,86.5 \%$ patients had preinduction modified bishop's score 3-4 and 3.5\% had a score of 5 . $25 \%$ patients had a score after 4 hrs of induction between 5
-8. Vaginal delivery within $24 \mathrm{hrs}$ of induction was obtained in $65.95 \%$. mean induction to the delivery interval was 14.16 hours. 43 patients required oxytocin augmentation $(22.87 \%)$. Mean no. of misoprostol required for a successful outcome was 0.4 .

\begin{tabular}{lcc} 
Table 3: Mode of delivery & & \\
Mode & N (188) & Percentage \\
Vaginal deliveries & 124 & $65.95 \%$ \\
Preterm Vaginal Deliveries & 3 & $2.4 \%$ \\
Full Term Vaginal Deliveries & 121 & $97.5 \%$ \\
LSCS & 64 & $34.04 \%$ \\
\hline
\end{tabular}

Causes of induction of labour included postdate $(49.46 \%)$ which was significantly followed by pregnancy-induced hypertension (14.42\%). Prelabour rupture of membranes included $21.27 \%$ which was also a significant percentage.

\section{Table 4: Indications of induction of labour}

\begin{tabular}{lcc} 
Indications of induction & $\mathbf{N}(\mathbf{1 8 8})$ & Percentage \\
Postdate & 93 & $49.46 \%$ \\
Pih & 29 & $14.42 \%$ \\
Oligohydramnios & 9 & $4.78 \%$ \\
Iugr & 17 & $9.04 \%$ \\
Prom & 40 & $21.27 \%$ \\
Term prom & 21 & $11.11 \%$ \\
Preterm prom & 19 & $10.16 \%$ \\
\hline
\end{tabular}

Common causes of LSCS were meconium liquor post rupture of the membrane which accounted for 28 cases $(43.75 \%)$, followed by non-reassuring NST consisting of decelerations or fetal tachycardia or bradycardia which accounted for 21 cases $(32.81 \%) .7$ cases had tachysystole and non reassuring which were taken for LSCS later.

\section{Table 5: indications of LSCS}

\begin{tabular}{lcc} 
Indications of LSCS & N (64) & Percentage \\
Meconium Liquor & 28 & $43.75 \%$ \\
Non reassuring NST & 21 & $32.81 \%$ \\
Tachysystole & 7 & $10.93 \%$ \\
Failure of Induction & 5 & $7.81 \%$ \\
Abruption & 3 & $4.68 \%$ \\
\hline
\end{tabular}

Table 6: Maternal complications

\begin{tabular}{lcc} 
Maternal complications & N (188) & Percentage \\
Post partum hemorrhage & 17 & $9.04 \%$ \\
Maternal sepsis & 24 & $12.76 \%$ \\
Wound gape & 4 & $2.12 \%$ \\
Maternal deaths & 0 & $0 \%$ \\
\hline
\end{tabular}


Not many significant maternal complications were noted. It included postpartum hemorrhage in 17 cases $(9.04 \%)$. There were 24 cases $(12.76 \%)$ which mainly included postpartum fever on day 2 or 3 of LSCS, which were managed conservatively without much morbidity. The overall maternal outcome was found satisfactory.

\section{Table 7: Neonatal outcome}

\begin{tabular}{lcc} 
Neonatal outcome & N (188) & Percentage \\
NICU Admission & 14 & $7.44 \%$ \\
Low birth weight babies & 47 & $25 \%$ \\
Very low birth weight babies & 5 & $2.65 \%$ \\
Respiratory distress & 23 & $12.23 \%$ \\
\hline
\end{tabular}

Neonatal outcomes seen were respiratory distress in 23 cases which were mild distress post-delivery which were managed with oxygen administration. Only 9 babies with severe respiratory distress was shifted to NICU for observation. The rest of NICU admissions were very low birth weight babies $5(2.65 \%)$. All the babies had a good outcomes with no major morbidity.

\section{DISCUSSION}

Low dose oral misoprostol for induction of labour is effective in giving vaginal deliveries within 24 hours with less complications and fewer side effects. Our results were consistent with that of the study of Marilyn Morris conducted at Papua New Guinean Women Hospital. A total of 6167 patients was screened and 209 (3\%) patients met the criteria for oral misoprostol ${ }^{18}$.

The median age was 27 years. Women who underwent induction of labour, maximum were post date $117(56 \%), 22 \%$ (45) had prelabour rupture of membranes. $13 \%$ had preeclampsia, 5\% had IUGR. 90\% (188) patients had vaginal deliveries. 21 patients underwent LSCS. Causes of LSCS were fetal distress (38\%). 8 babies were admitted in neonatal care out of which 4 were due to low birth weight and 3 due to neonatal sepsis. Out of 20 babies delivered by LSCS, 15 were admitted in neonatal care for routine observation and 2 for meconium aspiration syndrome.

Another study done by Mieke LG et al. on induction of labour with oral misoprostol vs that of foley's induction. 932 patients were induced with oral misoprostol and 927 patients were induced with foley's. section occurred in $16.8 \%$ (155) patients of misoprostol as compared to that of foley's (185) $20.1 \%$ (19). In another study, Acharya $\mathrm{N}$ et al. compared the role of Foley's catheter in the induction of labour with misoprostol and found no significant statistical difference in the mode of delivery. The number of cesarean sections, instru- mental deliveries, and spontaneous vaginal deliveries were comparable in both the groups ${ }^{20}$.

In a comparative study conducted by Ahmad B et al., St. Stephen's College, New Delhi, in 2017, between sublingual, oral, and vaginal route of misoprostol induction, the mean age of patients in the oral group were 23.36 years with mean gestation of 38.81 weeks. The mean bishop's score was 3.12 .

The most common indication for the induction of labour was postdate pregnancy (34\%) which was similar to our study. Other common indications were pregnancy-induced hypertension, oligohydramnios and intrauterine growth restriction. Mean doses of misoprostol required in the oral group were 2.1. rate of LSCS in the oral group was $20 \%$. Hypertonus occurred in $2 \%$ patients. And an indication of the section was $10 \%$ due to meconium-stained liquor. Non-stress test was non reassuring in $5 \%$ of the patients requiring LSCS in oral misoprostol group.

In neonatal outcome, Apgar score was good in all babies at 5 min in oral group. 1 minute apgar score $<7$ were found in 2 babies in the oral group. There were no major maternal and neonatal morbidities in the oral misoprostol induction group.

Cochrane trials - 75 randomized trials (13793 women) found oral misoprostol effective as the current method of induction. 9 trials (1282 women) found oral misoprostol equal to intravenous oxytocin. 9 trials (1109 women) of oral misoprostol with placebo found oral misoprostol more effective than placebo in vaginal deliveries within 24 hours with less LSCS.

\section{CONCLUSION}

FDA has approved misoprostol during pregnancy. Due to its cost-effectiveness and lesser side effects with safety and good uterotonic and cervical ripening properties, it can be used as a promising agent for the induction of labour in low doses at frequent intervals orally.

It has a high rate of vaginal deliveries within 24 hours with lessen the incidence of LSCS, failed induction, and lesser requirement of oxytocin for augmentation of labour with lesser NICU admissions.

\section{Acknowledgement: None}

Conflict of interest: Nnone

Financial support: None

\section{REFERENCES}

1. Hofmeyr G, Alfirevic Z, Matonhodze B, et al. Titrated oral misoprostol solution for induction of labour: a multi-centre, randomised trial. RCOG2001, Br J Obstet Gynaecol. 2001;P11: S0306-5456(01)00231-5. 
2. Mackenzie I. Induction of labour at the start of the new millennium. Reproduction. 2006; 131(60): 989-98.

3. Sanchez- Ramos L, Kuntiz M, Wears L. Misoprostol for cervical ripening and labor induction: A meta-analysis. Obstet Gynaecol. 1997; 89: 633-42.

4. Saeed G, Fakhar S, Nisar N et al. Misoprostol for term labour induction: a randomized controlled trial. Taiwan J Obstet Gynecol. 2011;50(1):15-9.

5. Pollnovv D, BroeKhuizen F. Randomized double blind trial of prostaglandin E2 intravaginal gel versus low dose Oxytocin for cervical ripening before induction of labor. Am J Obstet Gynaecol. 1996; 174:1910-6.

6. Alfirevic Z, Keeney E et al. Labour induction with prostaglandins: a systematic review and network meta-analysis. BMJ. 2015; 350: 217:350.

7. J. Tang N, Kapp M et al. "WHO recommendations for misoprostol use for obstetric and gynecologic indications," International Journal of Gynecology \& Obstetrics. 2013; 121(2): 186-189.

8. G. J. Hofmeyr, "Oral misoprostol is as safe as Foley catheter for labour induction...or is it?" The Lancet, 2016; 387(10028): 1593-1594.

9. Aronsson A, Bygdeman $\mathrm{M}$ et al. Effects of misoprostol on uterine contractility following different routes of administration. Human Reproduction. 2004; 19(1): 81-84.

10. Tessier F, Dansereau J. A double-blind randomized controlled trial comparing oral misoprostol to vaginal prostaglandin E2 gel for the induction of labour at or near term. Am J Obstet Gynecol. 1997; 176:S111.

11. Windrim R, Bennett $\mathrm{K}$ et al. Oral administration of misoprostol for labour induction: a randomized controlled trial. Obstet Gynecol. 1997; 89:392-7.
12. Adair C, Weeks W, Barrilleaux S, et al. Labour induction with oral versus vaginal misoprostol: a randomized, double-blind trial. Am J Obstet Gynecol. 1998; 178:S93.

13. Kwon J, Davies G, Mackenzie V. A comparison of oral and vaginal misoprostol for induction of labour at term: a randomised trial. Br J Obstet Gynecol. 2001; 108: 23-6.

14. Wing D, Ham D, Paul R. A comparison of orally administered misoprostol with vaginally administered misoprostol for cervical ripening and labour induction. Am J Obstet Gynecol. 1999; 180: 1155-60.

15. Toppozada M, Anwar M, Hassan $\mathrm{H}$ et al. Oral or vaginal misoprostol for induction of labour. Int J Gynecol Obstet. 1997; 56: 135-9.

16. Kadanali S, Kucukozkan T, Zor N, et al. Comparison of labour induction with misoprostol vs. oxytocin/prostaglandin E2 in term pregnancy. Int J Gynecol Obstet. 1996; 55: 99-104.

17. Jain, V., L. Waghmare, $T$ et al. "SNAPPS Facilitates Clinical Reasoning in Outpatient Settings." Education for Health: Change in Learning and Practice 31, no. 1 (2018): 59-60.

18. Morris, Marilyn \& Bolnga et al. Safety and effectiveness of oral misoprostol for induction of labour in a resource-limited setting: A dose escalation study. BMC Pregnancy and Childbirth.

19. Mol BW, Bloemenkamp K. Progress of labor in women induced with misoprostol vs the Foley catheter. Am J Obstet Gynecol. 2014;210(1):91.

20. Acharya, N., Gadge A et al. Mechanical Cervical Ripening with Foley Catheter Balloon: Rekindling a Forgotten Art. Journal of SAFOG. 2018; 10(1): 1-4. 